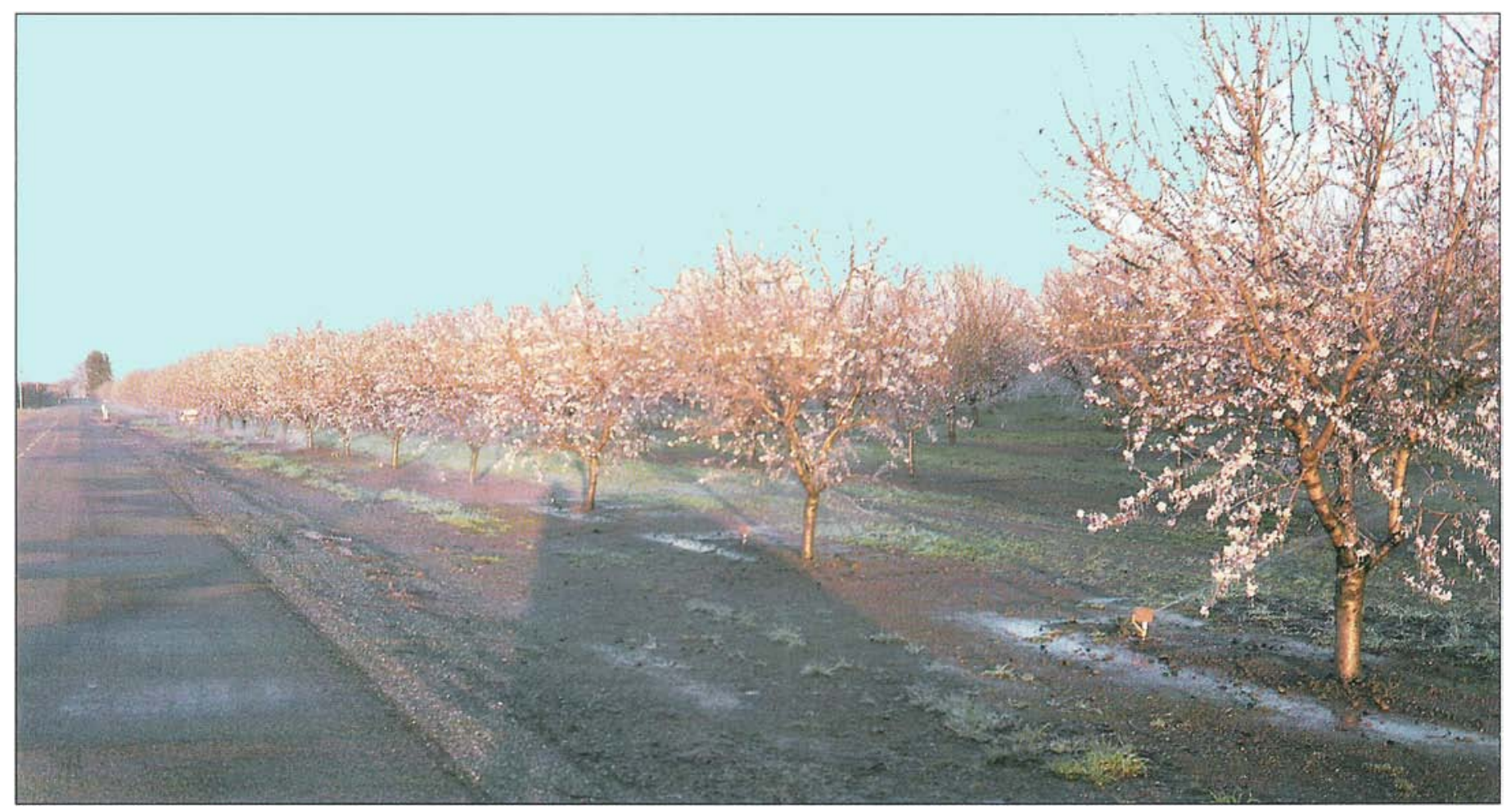

Almond orchard north of Chico which was site of ground cover experiments.

\title{
Ground cover height affects pre-dawn orchard floor temperature
}

\author{
R. L. Snyder $\quad$ Joseph H. Connell
}

Ground covers can affect the balance of heat between soil and air during radiation freezes in orchards; their careful management, therefore, can provide protection. During daylight, shortwave (solar) radiation strikes the ground and some energy is stored in the soil and in floor vegetation. A portion of this is emitted at night as longwave (terrestrial) radiation. When less heat is stored in the soil during the day, less is available for release at night. As a result, orchard air temperatures are lowered and the potential for freeze damage increases.

\section{Energy relationships in orchards}

Temperature decreases at night, depending on heat flux density (heat transfer per unit area per unit time) to and from an orchard. The units of heat flux density are watts per square meter $\left(\mathrm{W} \mathrm{m}^{-2}\right)$. Figure 1 shows a heat flux density balance measured within a Texas citrus grove on February 23-24, 1968 during a radiation freeze. A similar balance is likely in an al= mond orchard. Radiation freezes are characterized by calm winds and clear skies.

The main components of heat or energy transfer during a radiation freeze include (1) upward long-wave radiation, (2) downward long-wave radiation, (3) air-tocrop heat transfers, and (4) soil-to-crop heat transfers. Positive heat flux represents a gain by an orchard; negative flux represents heat loss. During a typical radiation freeze night, more heat leaves an orchard through upward long-wave radiation than is gained by downward radiation, air-tocrop heat transfer, and soil-to-crop heat transfer combined. Net loss is approximately $18 \mathrm{~W} \mathrm{~m}^{-2}$. Changing weather during the night affects heat flux, net heat loss, and the rate temperatures fall.

Radiation. Nighttime radiation loss from a crop to the sky decreases slowly during the night as surfaces cool. Loss depends mainly on the temperatures of the crop and soil. Downward radiation from the sky depends on the effective sky temperature and can change considerably

\begin{abstract}
When pre-dawn temperatures of bare soil and ground covers were measured in a Northern California almond orchard, bare soil was generally found to be the warmest; however, after several days of low solar radiation and strong, dry winds, ground cover surfaces were found to be warmer. This finding was attributed to the drying of the surface soil crust which can reduce soil heat transfer to and from moist layers below. Wetting dry soil after an episode of dry winds restores the soil's ability to store heat during the day and to release it at night.
\end{abstract}


with formation of clouds or fog, which are warmer than clear sky. Downward radiation increases because the clouds or fog are warmer than a clear sky. Consequently, the downward long-wave radiation into an orchard is greater during cloudy or foggy weather, thereby reducing net heat loss and slowing or stopping temperature drops.

Air-to-crop transfers. The air's heat content is an added source of energy to orchards. When air temperature is higher than crop temperature, heat is transferred from air to crop. During most freeze nights, transfer of heat from air to crop is enhanced by increased wind speed. Temperature typically increases with height above the ground during a radiation freeze and increasing wind speed mixes warm air aloft with colder air near the surface. This supplies additional heat from air within the orchard.

Soil-to-crop transfers. A soil's ability to transfer and store heat determines soil temperature changes and heat flux to and from the surface. Most heat exchange occurs at the soil surface; the greatest daily and annual variations in temperature are therefore at the soil surface. The range of temperature variations decreases with soil depth; daily, there is little change below 30 cm deep.

Moist soils are more capable than dry soils of transfering and storing heat, so more heat from daytime solar radiation is stored deeper in moist soil. The result: Soil to crop and decreases the rate of cooling

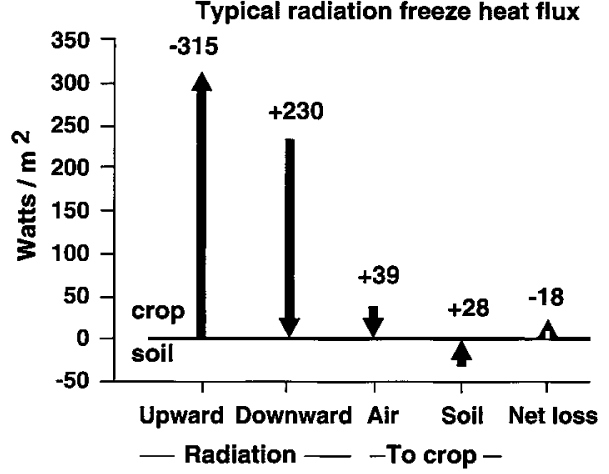

Fig. 1. Heat flux densities within a citrus grove are depicted during a radiation freeze February 23-24, 1968 in Weslaco, Texas. (Reported by T. R. Mee, Mee Industries, Inc., San Gabriel, California, 1979.)

surface temperature varies less and the daily minimum temperature of moist soil is higher than for a dry soil. A warmer soil surface supplies more heat to the orchard because the air in contact with the soil is warmed and there is greater surface radiation to the sky and trees. Consequently, there is more heat transfer from soil to crop when the soil surface temperature is warmer.

Orchard floor vegetation affects daytime heat balance and heat storage in the soil. More solar radiation is reflected from a green vegetative surface than from dark, bare soil, so ground cover reduces daytime absorption. Some energy is absorbed and stored by vegetation, but vegetation has less capacity for storage than does soil. Without ground cover, more radiation

TABLE 1. Daily mean temperature, daily mean dewpoint temperature, mean wind speed in meters per second $\left(\mathrm{m} \mathrm{s}^{-1}\right)$ and miles per hour $(\mathrm{mph})$, and solar radiation in MegaJoules/square meter $\left(\mathrm{MJ} \mathrm{m}^{-2}\right)$ per day and langleys (ly) per day on and before date of data recording

\begin{tabular}{|c|c|c|c|c|c|c|}
\hline \multirow[t]{2}{*}{ Date } & \multirow{2}{*}{$\frac{\text { Temperature }}{{ }^{\circ} \mathrm{C}}$} & \multirow{2}{*}{$\frac{\text { Dewpoint }}{{ }^{\circ} \mathrm{C}}$} & \multicolumn{2}{|c|}{ Wind speed } & \multicolumn{2}{|c|}{ Radiation } \\
\hline & & & $m s^{-1}$ & $m p h$ & $M J m^{-2}$ & ly \\
\hline Jan. 8, 1987 & 4 & 0 & 1.1 & 2.5 & 7.0 & 167 \\
\hline Jan. 9,1987 & 4 & -1 & 1.0 & 2.2 & 9.3 & 222 \\
\hline Jan. 10,1987 & 1 & 0 & 1.6 & 3.6 & 4.6 & 110 \\
\hline Jan. 11,1987 & 1 & 0 & 1.3 & 2.9 & 1.7 & 41 \\
\hline Jan. 12,1987 & 0 & -1 & 1.1 & 2.5 & 2.0 & 48 \\
\hline Jan. 13,1987 & 5 & -5 & 3.8 & 8.5 & 10.0 & 239 \\
\hline Jan. 14,1987 & 6 & -4 & 3.0 & 6.7 & 9.8 & 234 \\
\hline Apr. 4, 1988 & 14 & 7 & 1.4 & 3.1 & 21.9 & 523 \\
\hline Apr. 5, 1988 & 16 & 6 & 1.3 & 2.9 & 22.6 & 540 \\
\hline Apr. 6,1988 & 19 & 9 & 1.8 & 4.0 & 19.9 & 475 \\
\hline Apr. 7, 1988 & 16 & 4 & 3.5 & 7.8 & 23.2 & 554 \\
\hline Apr. 8,1988 & 15 & -2 & 4.2 & 9.4 & 22.6 & 540 \\
\hline Apr. 9, 1988 & 17 & 5 & 1.8 & 4.0 & 24.4 & 583 \\
\hline Mar. 12, 1989 & 13 & 7 & 3.2 & 7.2 & 18.2 & 435 \\
\hline Mar.13, 1989 & 11 & 4 & 1.8 & 4.0 & 19.7 & 471 \\
\hline Mar. 14, 1989 & 9 & 0 & 1.7 & 3.8 & 20.6 & 492 \\
\hline Mar. 20, 1989 & 5 & 4 & 2.1 & 4.7 & 20.8 & 497 \\
\hline Mar. 21, 1989 & 8 & 8 & 1.2 & 2.7 & 15.1 & 361 \\
\hline Mar. 22, 1989 & 7 & 8 & 1.1 & 2.5 & 19.1 & 456 \\
\hline Apr. 12,1989 & 23 & 11 & 2.4 & 5.4 & 20.5 & 490 \\
\hline Apr. 13,1989 & 22 & 14 & 1.8 & 4.0 & 24.5 & 585 \\
\hline Apr. 14,1989 & 21 & 14 & 1.8 & 4.0 & 22.8 & 545 \\
\hline
\end{tabular}

reaches the soil where the absorption, transfer, and storage of heat are better.

Figure 1 illustrates the relative amounts of heat flux from air to crop and from soil to crop on a typical radiation freeze night. Heat flux from air to crop can fluctuate considerably at night, depending on wind speed and temperature inversions. Heat flux from soil to crop is less responsive to weather changes during the night, but proper floor management can increase the heat flux density enough to protect a crop from freeze damage during dry, calm conditions.

Fog's effects. Both clouds and fog formation increase downward long-wave radiation and reduce the net loss of heat from an orchard. However, fog also releases latent heat to the environment when the water vapor condenses. In response to fog, orchard temperatures have been observed to rise a few degrees and to remain relatively stable for the rest of the night.

Effects of dew or frost. Formation of dew or frost on the orchard floor slows the drop in air temperature because the condensation releases stored latent heat to the environment. Considerable heat is released when dew or frost forms and that heat replaces some of the net heat loss. Dew or frost forms at higher air temperatures on nights when the vapor content of the air is high, so freeze damage is less likely on nights with a high humidity (high dewpoint temperature).

Advection freezes. In advection freezes, the temperature often continues to drop, even with strong winds, because cold air is blowing into the orchard and replacing warmer air that was there previously. The advected air is cooler than air it replaces, so heat flux from the air to crop is reduced. If the air is colder than the trees, the heat flux can be from the crop to air (that is, the air-to-crop heat flux is negative). Advection freezes typically have greater net heat loss than do radiation freezes, and air temperature may drop rapidly when the wind blows.

\section{Orchard floor management}

Orchard floor management options that can be employed to reduce the potential for freeze damage include mowing the ground cover or using herbicides to slow growth or kill the cover. On the other hand, ground covers can benefit tree crops because they provide habitats for beneficial insects, add organic matter to the soil, improve water infiltration, reduce dust, and minimize soil compaction and erosion. Although ground covers are often considered detrimental to freeze protection, their benefits may be worth considering in managing orchard floors. 
Although the effects of ground cover management on daily minimum temperatures are, theoretically, well understood, the actual effects on daily minimum temperatures afforded by different management styles are not well known. Most protection values given in the literature are based on testimonials rather than on careful measurements. The difficulty occurs because small changes in radiation balance, heat transfer from the air, and latent heat transfer from dew or fog can easily mask differences due to floor management. However, orchard floor management can occasionally make the difference between freeze damage and little or no damage.

\section{Microclimate effects}

Air temperatures within an orchard vary because the microclimate is complex. The authors have observed air temperature differences as large as $2.7^{\circ} \mathrm{F}\left(1.5^{\circ} \mathrm{C}\right)$ within a small, uniformly managed, almond orchard. These natural variations may be due to cold air drainage or edge effects as air from outside flows into and mixes with air inside the orchard. The natural temperature variations are similar in magnitude to the expected temperature effects from ground cover management.

An extensive treatment area must be used to assess the effects of ground cover treatments on air temperature. Treatments applied to large areas are likely, however, to differ in temperature due to natural factors other than ground cover height. These differences may mask the treatment effects. On the other hand, if treatments are applied to small areas with uniform microclimates, the area may be too small for the ground cover treatments to influence air temperature. This dilemma can be solved by replicating ground cover treatments within a small, uniform microclimate and measuring surface rather than air temperature. Air temperature is highly correlated with surface temperature and treatment effects should be reflected in air temperature when the ground cover management covers a larger area. During radiation freeze nights, wind speeds are typically light, so the influence of limited treatment area on surface temperatures should be small.

\section{The present study}

To gain insight into the freeze protection afforded by different ground covers, experiments were conducted in an almond orchard during the winters of 1987, 1988, and 1989. The objectives were to determine (1) whether ground vegetation height affects pre-dawn orchard floor tem-

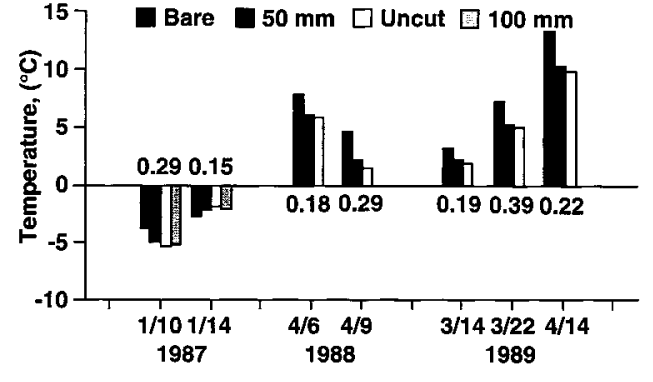

mean of measurements taken in both easterly and westerly directions was analyzed. Because there was little difference in measurements taken in easterly or westerly directions, the IR thermometer was aimed only in an easterly direction in 1989.

\section{Results}

To obtain information on conditions preceding measurements, daily weather data on and for a few days preceding measurements were gathered (table 1). Vari-

Fig. 2. Orchard floor surface temperatures were measured with an infrared thermometer over (1) bare soil, (2) mowed 2-inch (50-mm) ground cover, (3) uncut 6- to 12inch (150- to $300-\mathrm{mm})$ ground cover, and (4) mowed 4-inch (100-mm) ground cover (1987 only). Only days with ANOVAs indicating treatment differences at $P<0.05$ level were included. LSDs in ${ }^{\circ} \mathrm{C}$ at the 0.05 level are indicated for each date.

peratures and (2) whether tree foliage growth lessens the importance of ground covers in providing freeze protection.

Experiments were conducted in an almond orchard north of Chico. Each 8-m $x$ 8-m plot was located in the middle of four trees. In 1987, the experiment was arranged in a latin square design (four rows and four columns). Cover treatments were (1) uncut with heights between 6 to 12 inches (150 and $300 \mathrm{~mm}$ ), (2) mowed to 4 inches (100 mm), (3) mowed to 2 inches $(50 \mathrm{~mm})$, and (4) bare soil. In 1988 and 1989, a randomized complete block design with six blocks and three treatments within a block was employed. The three treatments were (1) uncut, (2) mowed to 2 inches, and (3) bare soil.

In the bare ground treatment, Roundup was sprayed to kill the resident vegetation (annual bluegrass, chickweed, and filaree). Residual material was raked from bare soil plots. Care was taken to measure floor temperature where the ground cover was closest to the desired treatment height. When the ground cover was wet and floor temperature was below $32^{\circ} \mathrm{F}\left(0^{\circ} \mathrm{C}\right)$, walking was permitted only on the edge of a plot to minimize ice formation. Ground cover heights were noted throughout the trials, but slow growth resulted in little change in height during the period of observation.

Floor temperature was measured using a hand-held infrared (IR) thermometer sensitive in the range of 8 to $14 \mu \mathrm{m}$ and the emissivity set at $\epsilon=0.98$ (the $\epsilon$ value is typical of wet soil and vegetation). The $\mathbb{R}$ thermometer view angle was $5^{\circ}$ and it was always aimed at $45^{\circ}$ from vertical. Readings were taken just before sunrise when the floor temperature is likely to be near the daily minimum. In 1987 and 1988, the ances in floor temperatures were computed for each date, using the testing hypothesis that ground cover heights affect floor temperature. On most nights when measurements were taken, the treatments significantly affected floor temperature (table 2).

Figure 2 illustrates the mean floor temperatures by treatment for dates with $\mathrm{P}<$ 0.05 in table 2. Least significant differences (LSDs) at the $\mathrm{P}=0.05$ level are indicated for each date. Floor temperatures below $32^{\circ} \mathrm{F}\left(\theta^{\circ} \mathrm{C}\right)$ occurred only on measurement dates in 1987, but treatment effects on measured floor temperatures above $32^{\circ} \mathrm{F}$ are still informative. On all dates but January 14,1987, bare soil was significantly warmer than the treatments with ground cover. On two dates, the uncut ground cover was significantly colder than the other treatments. After the cover attained or exceeded a height of 2 inches, however, there seemed to be little or no difference in pre-dawn floor temperatures.

The difference noted on January 14 may be attributed to weather before the measurement night (table 1). Solar radiation was low on January 11 and 12 followed by dry, windy conditions January 13. The wind continued during the night of January 13-14 and died down just before temperatures were recorded. It is likely that the bare soil's surface crust was desiccated by the drying winds. A drier soil crust may have reduced thermal conductivity and impeded transfer of heat to

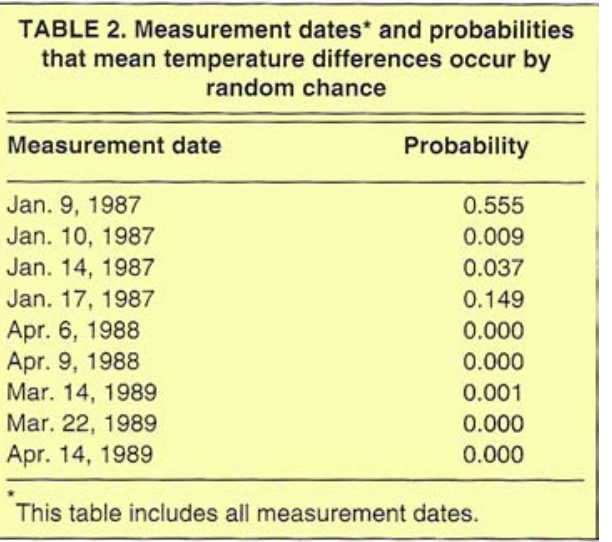


deeper soil layers, resulting in less soil heat storage. Drying winds can also remove water from ground cover plots, but the water is extracted by the roots from deeper in the soil. In that case, the surface crust is less likely to be desiccated and heat transfer to deeper layers is less affected.

It is also possible that the emissivity of a dry soil crust is less than $\epsilon=0.98$ used with the IR thermometer. If $\in$ was less than 0.98 , the bare soil temperature measured with the IR thermometer would be inaccurate (that is, higher than the actual surface temperature). For each 0.01 decrease in the $\in$ setting, IR thermometer measured temperature is increased by approximately $1.3^{\circ} \mathrm{F}\left(0.7^{\circ} \mathrm{C}\right)$. Although this may partially explain the colder bare soil January 14, wetting the soil after several days of strong drying winds is still recommended.

H. B. Hanson of the National Weather Service reported in the 1950s that ground cover management became less important as tree foliage developed. This was attributed to increased daytime shading of the orchard floor by tree foliage. Data from April 14, 1989 show, however, that bare ground was approximately $5.4^{\circ} \mathrm{F}\left(3^{\circ} \mathrm{C}\right)$ warmer than the vegetated floor, even with $40 \%$ ground shading by tree foliage.

\section{Conclusions}

The results presented here confirm that pre-dawn floor temperatures in an almond orchard are likely to be highest when the floor is bare of vegetation. There seems to be little difference in the effect of ground cover height on pre-dawn surface temperature when the ground cover is 2 inches $(50 \mathrm{~mm})$ or taller. Orchard floor management affects freeze protection at least until trees attain $40 \%$ ground shading. Following several days of low solar radiation and drying winds, bare soil may be colder than soil with a ground cover, a common occurrence in California. Dry soil surface layers, therefore, should be rewetted, if possible, after windy periods to improve soil heat transfer and storage. When freezing temperatures are predicted, rewet the soil a day or two before the freeze night.

R. L. Snyder is Extension Biometeorologist, Department of Land, Air and Water Resources, UC Davis, and J. H. Connell is Farm Advisor, Butte County.

Funding for this research was provided by the Almond Board of California. Hennigan Farms in Chico, California provided the research site. The authors thank Robert Hennigan for assisting them with plot preparation and data gathering.

\title{
Dupuit-Forchheimer approximation may underestimate groundwater flow to San Joaquin River
}

\author{
Mark E. Grismer $\square \quad$ Elias A. Rashmawi
}

\begin{abstract}
Based on the commonly used Dupuit-Forchheimer approximation, estimates of groundwater contributions to flows in the San Joaquin River may be too low. Why? Because the vertical groundwater flows through the base of the channel have been neglected in estimates. Scientists found that flows have been underestimated by as much as $25 \%$; such flows may degrade river water quality more than anticipated. The findings suggest the need to closely monitor subsurface runoff. A new look at the estimates is important to the development of water/salinity management plans.
\end{abstract}

For several years, as part of an analysis of the San Joaquin River's water quality, groundwater flow models were developed to measure the amount of groundwater entering the river along a 60-mile reach from Lander Avenue in Merced County to Vernalis in Stanislaus. Although groundwater flows to the river are relatively small, compared with the total river flows (California Agriculture, November-December 1987), their contributions of salt, boron, and other trace elements could be significant. Information about these contributions is needed to develop a basin water plan and water/salinity management plans.

In refining techniques used in the river water quality model, errors in estimating groundwater flow to the river were found and traced to an uncertainty in estimating monthly groundwater recharge to the land areas up to 2 miles distant on either side of the river, and correct parameterization of the hydraulic conductivity or permeability of the shallow groundwater zone. After improving our data base, we found that groundwater flow estimates, based on the
Dupuit-Forchheimer (D-F) approximation, were consistently 5 to $50 \%$ lower than estimates made without using the approximation or than estimates based on U.S. Geological Survey (USGS) spot measurements along the river. For example, USGS mass balance estimates of groundwater flow based on surface flow measurements for river miles numbered 108 and 118 were 57 and 106 acre-feet per month, respectively, compared with 34 and 54 acre-feet per month for these locations, respectively, estimated from a D-F approximation based groundwater model.

Because of these discrepancies, we undertook a detailed study of the D-F approximation itself as it applies to estimating groundwater flows to rivers or unlined canals.

\section{D-F approximation}

In a discussion of the approximation in 1937, Morris Muskat of Gulf Research and Development Co. named it after both Dupuit and Forchheimer (French and German engineers, respectively, who independently developed this approximation to groundwater flows such that the governing differential equations could be solved analytically for practical drainage problems). He indicated that the approximation assumes that "for small inclinations of the free surface of a gravity-flow system, the streamlines can be taken as horizontal, and are to be associated with velocities which are proportional to the slope of the free surface, but are independent of the depth." In other words, the D-F approximation assumes that all groundwater flow, or velocity, is in the horizontal direction only, and that the magnitude of this flow or velocity is proportional to the slope of the water table, or free surface. All vertical flows, or velocities resulting from infiltration and seepage, or the changing flow geometries resulting from geologic formations or water channels, are ignored because the slope of the water table is presumed to be mild. For steady, unconfined groundwater flow, the free surface is the continued on page 13 